\title{
The Implementation of Social Capital Component Amoung High schools in city of Izeh
}

\author{
Masoud mohammadi, Seyyed Ali Siadat, Mohammad mohammadisadr \\ ${ }^{1}$ MA student,Islamic Azad university, Shahrekord,Iran \\ ${ }^{2}$ Associate Professor, Department of educational science, faculty of psychology\& educational sience, University \\ of Isfahan,Isfahan,Iran; \\ ${ }^{3}$ Ph.D student,Department of education, faculty of psychology\& educational siences, university of Isfahan,Iran,
}

\begin{abstract}
The aim of this research was measure of proving social capital components at the high schools Izeh city. Method of research was a descriptive and statistical community was including all of the teachers of high school course in Izeh city which were 452 people. The bulk of statistical sample using Karjis and Morgan table was obtained 207 people but returned questionnaires were 191 questionnaires. The method of classical random sampling was proportional to the statistical community of female and male teachers. The tools of measuring were a social capital questionnaire including 35 items based on SCAT model. Contextual reliability using Kandal coefficient 0.65 was obtained and reliability of the questionnaire was obtained by Alpha coefficient of Cronbach 0.83. To analyze data, the statistical methods of one variable $t$ and multivariable variance analysis were used. The results were indicated in point of view of teachers, trust, cooperation, commitment, reciprocal relations, attitudes, integration, social norms components were proved in the high schools of Izeh city and this finding was significant as statistical aspect. Results showed that in the view of teachers trust, cooperation, commitment, reciprocal relations, attitudes, integration, and social norms of social capital proved in high schools of Izehcounty and this finding was significant statistically
\end{abstract}

Keywords: social capital, teachers, high school

Submitted Date 11 June 2013

Accepted Date: 17 July 2013

\section{Introduction:}

Social capital is one of the new concepts that nowadays are discussed in economic and social surveys. The social capital concept is an interfiled concept. First, the social capital was discussed in the field of sociology, and then it was discussed in the fields related to economy and got in their literature. After that it was discussed in the field of management, then the effect and the role of social capital in organizations and its significance was considered. (Galvani, 1999). Social capital is something that forms the human and financial capitals and leads to a political, cultural and economical action by forming a consistent construction. Social capital is the missing ring of back warding of countries. (Biker, 2003). Social capital is a collection of norms in the social system that cause to boosting the collaboration of the society members and to descending the costs of exchanges and communications. (Fukuyama, 2000). Fortifying the Social capital causes to formation of strength and social visible and invisible connections in the society and increases the collaboration and trusting feeling in the society, but, decreasing the social capital makes the communications between people so complicating and expensive. Trust will leave, morals will be languished and people's behavior with each other will be the way that they meet each other momentary and just once and they do not have to live together and in one society. Considering the role and significance of Social capital in the organizations, the present study has investigated the achieving variables of social capital in the high schools of IzehCounty.

\section{Methodology :}

As this research is going to investigate the achieving variety of Social capital through teacher's opinions and the measurement instrument is a questionnaire. So the research procedure will be described and of survey kindest.

Participants: the present participants include all the teachers of high schools in IzehCounty and are 452.

Sample size: to determine the statistical sample size, Karjis and Morgan (1970) table were used. According to the calculations of this table for statistical sample size of 452 , the sample size of 207 will be suitable. So 207 questionnaires were distributed among the teachers but the field and backed. Questionnaires were 191.As the 
number of statistical population of male and female teachers in city of Izeh education was different, for considering their statistical population the coincidental sampling appropriate to the statistical population of male and female teachers was used.

Instrument: Social capital assessment tool (questionnaire)

The Social capital assessment tool was created based on the SCAT model. This questionnaire will measure the Social capital in seven variables: trust, collaboration, commitment, mutual relation, viewpoint, consolidation, and social norms. It consists of 35 questions with 5 scales (strongly agree, agree, uncertain, disagree, and strongly disagree). With scores of 5-4- 3- 2- 1 respectively.

The content reliability of the scale was $65 \%$ according to Kendal coefficient, which showed a suitable content reliability. Also, for measuring the validity of the scale the Cronbach alpha was used and the result was $83 \%$.

Data analysis: for inferential analysis of the data the t- test one variable was used.

\section{Analysis :}

The main research question:

\section{Has been achieved in high schools of Izeh?}

In inferential analysis for determining the meaningful level, t- test in level $\alpha=0.05$ was used and as the measured average (3) and t value is bigger than the critical amount in table (1.97), so it can be inferred that from the teacher's point of view, the social capital has been achieved in the high schools of Izeh county and this finding is also meaningful regarding the statistical calculations.

The first research question:

\section{Has trust variable of social capital has been achieved in high schools of Izeh county?}

In inferential analysis for determining the meaningful level, the $t$ - test in level $\alpha=0.05$ was used and as the measured average (3.10) is more than hypothetical average (3) and t value is bigger than the critical amount in table (1.97), so it can be inferred that from the teacher's point of view, the trust variable of social capital has been achieved in the high schools of Izeh county and this finding is also meaningful regarding the statistical calculations.

The second research question:

\section{Has collaboration variable of social capital has been achieved in high schools of Izeh county?}

In inferential analysis for determining the meaningful level, the $\mathrm{t}$ - test in level $\alpha=0.05$ was used and as the measured average (3.08) is more than hypothetical average (3) and $t$ value is bigger than the critical amount in table (1.97), so it can be inferred that from the teacher's point of view, the collaboration variable of social capital has been achieved in the high schools of Izeh county and this finding is also meaningful regarding the statistical calculations.

The third research question:

\section{Has commitment variable of social political has been achieved in high schools of Izeh county?}

In inferential analysis for determining the meaningful level, the $\mathrm{t}$ - test in level $\alpha=0.05$ was used and as the measured average (3.70) is more than hypothetical average (3), and t value is bigger than the critical amount in table (1.97), so it can be inferred that from the teacher's point of view, the commitment variable of social capital has been achieved in the high schools of Izeh county and this finding is also meaningful, regarding the statistical calculation.

The fourth question:

\section{Has mutual relation variable of social capital has been achieved in high schools of Izeh county?}

In an inferential analysis for determining the meaningful level, the t- test in level $\alpha=0.05$ was used and as the measured average (3.54) is more than the critical amount in the table, (1.97), it can be inferred that from the teacher's point of view, the mutual relation variable of social capital has been achieved in the high schools of Izeh county and this finding is also meaningful regarding the statistical calculations.

The fifth research question:

\section{Has viewpoint variable of social capital has been achieved in high schools of Izeh county?}

Has In inferential analysis was used a $=0.05$ in order to study the meaningful level of the test $(t)$ in the surface and with regard to obtained average ( 3.21 ) that is larger than assumed average ( 3 ) and also obtained " $\mathrm{t}$ " that is larger than critical value of table ( 1.87 ) so it can be concluded that the parameter of theory 
from social resources according to the view of teachers had been realized in the high schools in Izeh county and also this finding is meaningful on the statistical point of view .

\section{Sixth research question: Is unity parameter of social resources realized in high schools in Izeh County?}

In inferential analysis was used $a=0.05$ in order to study the meaningful level of the test $(t)$ in the surface and with regard to the obtained average ( 3.17 ) that is larger than assumed average ( 3 ) and also obtained " $\mathrm{t}$ " that is larger than critical value of table ( 1.97 ) so it can be concluded that the unity parameter from social resources according to the employees view had been realized in the high schools in Izeh county and also this finding is meaningful on the statistical point of view .

\section{Seventh research question: Are the parameters of social norms from social resources realized in the high schools in Izeh County?}

In inferential analysis was used $a=0.05$ in order to study the meaningful level of the test $(t)$ in the surface and with regard to the obtained average ( 3.98 ) that is larger than assumed average ( 3 ) and also obtained " $\mathrm{t}$ " that is larger than critical value of table ( 1.97 ) so it can be concluded that the parameters of social norms from social resources according to the view of teachers had been realized in the high schools in Izeh county and also this finding is meaningful on the statistical point of view .

\section{Discussion and conclusion}

The obtained results on the assurance value of the social resources in the high schools in Izeh County showed that according to the teachers view the social resources had been realized in the high schools in Izeh County and also this finding is meaningful on statistical point of view. In the other word, the parameters of reliance, partnership, obligation, counter relation, view, unity and social norms had been induced in the high schools in Izeh County. These findings have been conformed to the research findings by Eterly ( 2010 ), Angesterom and collaborators ( 2008 ), Dlaniand Keni ( 2005 ) and the research by Rekoena ( 2003 ) who did it in Spanish associations and this conformity is a representation of the importance of assurance of social resources in associations to obtain successful . While in the research by Hashemianfar was reported that insurance of social resources had been induced appearing of social inequality in association.But the findings of current research show that the managers of education organization in Izeh County had considered and supported the parameters of social resources. VILANOVA and JOSA also considered the social resources as a management phenomenon and explained the role of managers in assurance it as an essential role.

Also klman (1988) reported the role of social capital in the production of human capital is basic which the most important role among managers of an organization is.From the view point of teachers some matters like reciprocal trust among colleagues in the organization, sense of job safety, reciprocal relations of teachers and managers based on honest proved in the high schools of the Izeh county while some matters like expressing in the meetings of the organization, and free criticism to politics of the organization still isn't used in the high school of Izehcounty by managers. So, trust, sense of safety and confidence component exist at the staffs, as Stefan and Ibrahim (2004) reported trust is poor condition in existence of social capital in the organization and organization are having a high level of trust, have higher efficiency and they are able to confront with problems, because trust and confidence of their staffs to the organization and managers and also their colleagues, they always have necessary inflection and preparation to confront with problems, and to solve issues by using benefit and efficient ways. Also at the studies of J. Gnash (2003) and Cru (2002) were reported existence of trust in the organization is an important factor to growth and dynamic and they know it is necessary to be successful.

From the view point of a teacher's partnership component of social political was proved in the high schools of Izehcounty, because the means (3.08) were a little bigger than imaging means and it isn't significant statistically. In other words, from the viewpoint of teachers some matters like receiving authorities of organization from important suggestions, using ideas to edit the goals of an organization, and using individual ideas to politics in company weren't proved in the high schools of Izeh, only encouraging staff to participate in the following decisions of the organization was proved and also permission of creating and innovating were proved by managers of an organization in the high schools of Izeh county. This issue is due to that establishing politics and editing long time goals in the educational organizations of the province were performed by the manager of the educational ministry of our country and they are establishing politics to change in the future, capital of organization and financial power of it. Steven (1995) also knew necessary continuing social political to establish politics for future of nations and business. Also in the studies of Pranic (2011), Snlgru and Pikhart (2009), Skinner and Zakous (2008), Stefan and Ibrahim (2004), Ngish (2003), Cru (2002), Baikzahe (2007), Abdolbaghi (2007), Shari and Husseinirad (2008) and Hassanpur (2009) reported participation component is a factor to reinforce efficiency and participation of individuals in the organization.

From the view point of teachers some matters like neglecting personal interests because of the policy of group and organization, sense of harmony between problems of organization with individual problems, high 
effort of teachers, interest to job life in this organization were proved in the high schools of Izeh county . As in the studies of Pranic (2011), Snlhro and Pi Chart (2009), Skinner and Zakous (2008), Stefan and Ibrahim (2004), Kavoosi (2007), SalehiHikuei (2005), Shirvani (2003) and Tavasoli (2002), the existence of social capital is an avoidance issue in the present organizations and it's necessary to success of organization and to growth and development.

From the view point of teachers, reciprocal relations component of social capital was proved in the high schools of Izeh and these results are significant statistically. In other words, from the viewpoint of teachers some matters like establishing relations to mangers in order to solve job problems, friendly relation among colleagues, talking their colleagues about job and administrative problems, and often friends of staffs out of the organization were proved in the high schools of Izehcounty while satisfaction of job and organization and informal relations in the company weren't proved.

The existence of positive attitude to the organization is the most important component of social capital because positive attitude can due to more efficient and better function and double effort. The studies ofNgnesh (2003), Stefan and Ibrahim (2004), Dlani and Keni (2005), Vinstra and et.al (2008), Stenglar and Pikhart (2009) and Pranik (2011) were reported attitude dimension is the most important social capital.

From the view point of teachers, an integration component of social capital was proved in the high schools of Izeh and these results are significant statistically. In other words, from the viewpoint of teachers some matters like the commitment of staffs to the goals and rules of organization, participations of staffs in the problems of organization, respect of staffs to managers of organizations, and preferring work in this organization among teachers were proved in the high schools of Izehcounty, while the attitudes of staffs to long time goals of organization wasn't proved and they don't have a clear and light attitude to goals of educational organization.

So, what it's certain, integration and correlation between individuals would have a positive effect on procedure of organization and its cause to grow. Correlation of staffs can have happiness for them and it cause to increase physical and mental hygiene, as the studies of stone (1995), Purtiga (2005), Angstrum and et.al (2008), Snglru and Pikhaart (2009) was reported this matter.

From the view point of teachers, social norms of social capital were proved in the high schools of Izehcountyand these results are significant statistically. In other words, from the viewpoint of teachers some matters like self control of stuffs to do everything is forbidden for others, attention to populationdeficient to do affairs and behaviors among teachers, and effective and benefit relations among teachers were proved in the high schools of Izeh .

Attention to social norms of organization, cause to increase organizational citizen behavior and in this condition individuals can obtain the ability to decrease job stresses and he/ she would bear occupational stresses which fatigue of jobs will be decreased. The studies of Shareapour (2001) were reported the existence of social capital cause to mental grafts of individuals and these mental grafts cause to observe organizational social norms better know they knew it as one of the job priorities.

\section{References:}

[1]. Abdolbaghi,alimohammad.(2007) .social capital development in shade of trust.article collection of social capital and development conference.Tehran:specialized conferences office and international affairs.

[2]. Alvani,SeyedMohammad.(1999).role of management in production and development of social capital.Tadbir publication.no 100

[3]. Bicker, et al .(2003). social capital management;efficient policy in human resource management.Management and development.No 19

[4]. Beikzadehghalejogh,Shahram(2007) study of relation between social capital and personnel performance (case studying,bank mellat branch) m.a thesis Islamic Azad university,science and researcher unit

[5]. Fokoyama,f.(2000).order ends (social capital and its maintenance).Tavasoli translation.Tehran:Iranian society publication.

[6]. Hasan Pour,Nader. (1388). study of relation between social capital and mental welfare among socialwelfare and social provision ministry.M.a thesis in Tehran University

[7]. Kavosi,elahe.(2006).designation and social capital measurement pattern presentation.M.a thesis,Islamic as ad university,sciences and research branch

[8]. Shirvani, Ali.(2003). the influence of governmental organizational section on social capital.phd thesis Islamic AzadUniversity,sciences and research branch

[9]. Sharepor, Mohammad and hoseinirad, Ali (2008) study of relation between social capital and sport participation (case studying of 15-29 citizens of Babel)Harkat publication, no 37, page 131-153

[10]. Salehihicoi,mahdiye. (2005). study of relation between social capital network and mutual trust between individual and gender. M.a thesis, Azahra University

[11]. Tavasoli,GholamAbbas .(2002). social capital,invisible wealth,social capital and civil society.23 day month,Tehran:potency of civil society organizations center 